\title{
Economic aspects of an epidemic of haemorrhagic conjunctivitis in a rural community
}

\author{
D K SRINIVASA ${ }^{1}$ AND VIDAL D'SOUZA ${ }^{2}$ \\ From the Department of Preventive and Social Medicine, ${ }^{1}$ Jawaharlal Institute of Postgraduate Medical Education \\ and Research, Pondicherry and Goa Medical College, ${ }^{2}$ Panaji, Goa, India
}

SUMmARY The estimated economic loss due to an epidemic of acute haemorrhagic conjunctivitis in 1981 in a rural community of Goa studied by house-to-house survey of 7230 families is reported. Thirty-five per cent of families were affected and in $62 \%$ of these families more than three persons developed conjunctivitis. The affected were forced to be absent from work resulting in a reduction of the work force (loss of 7735 man days) and loss of income (Rs 1,33,300). The type of treatment followed and estimates of treatment cost are described. The economic consequences to the country of this widespread epidemic are described.

Acute haemorrhagic conjunctivitis occurred in India as a widespread epidemic in 1981. Similar outbreaks had been reported in 1971 from India, ${ }^{1}$ Ghana, ${ }^{2}$ and Japan. ${ }^{3}$ Such epidemics cause not only personal discomfort and suffering but also economic loss to the community due to their widespread occurrence. The loss could be due to 'direct costs', that is, cost of treatment and measures adopted to control the epidemic, and 'indirect costs' which would include loss of wages due to temporary incapacity and losses in the areas of trade and tourism. ${ }^{4}$ In the present paper, estimated economic loss due to temporary incapacity caused by an outbreak of acute haemorrhagic conjunctivitis in a rural community of Goa is described.

\section{Material and methods}

The study was conducted in the 18 villages covered by the Rural Health Centre (Mandur) of Goa Medical College from November 1981 to February 1982. The total population of the area was 28549 (1981 enumeration) residing in 7320 families. The data were collected by house-to-house visits to all families by paramedical staff of the health centre supervised by medical personnel. Data collection was preceded by two orientation sessions for the staff concerned.

The health centre maintains detailed family records which contain demographic information such as age, sex, occupation, etc, for each member of the family. These cards are updated annually. With the help of this information and personal interviews of those affected, the economic loss was estimated on the basis of (a) occupation of affected person(s), average income per month, duration of absence from work due to conjunctivitis (or temporary incapacity caused by it), consequent wage loss; and (b) cost of treatment, which included cost of drugs. These estimates were projected to the entire country by the probability method, using the population of the 1981 census.

\section{Results and discussion}

An outbreak of acute haemorrhagic conjunctivitis occurred in the months of May, June, and July 1981. A total of 8404 persons were affected, giving an attack rate of 294 cases per 1000 population. Mean duration of illness was 4 days $(\mathrm{SD}=1$ day).

Eighty two per cent of the cases occurred in June, $16 \%$ in July, and $2 \%$ in May. Thirty five per cent of all families were affected, and in $62 \%$ of the affected families three or more members had conjunctivitis. A positive correlation was observed between the proportion of persons affected and the family size $(r=0.66 ; p<0.001$ ), (figure).

Both eyes were affected in $99 \%$ of cases, a finding similar to that of other workers. ${ }^{2-4}$ The disease occurred in all age groups and both sexes (table 1). The highest incidence was in the 15-24 years age group, being $24 \%$ of all cases, followed by the $25-34$ years age group. The lowest incidence was among children under 5 years. The attack rate was slightly higher among males (302 per 1000) than females (287 per 1000).

The majority of affected persons $(74 \%)$ resorted to either self medication $(48 \%)$ or home remedies. Of the 


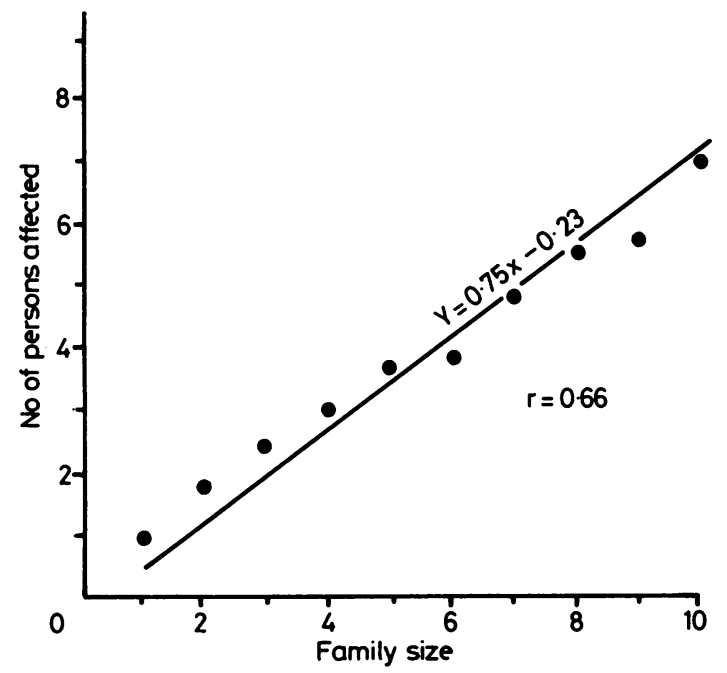

Correlation of persons affected and family size

Table 1 Distribution of persons affected by conjunctivitis by age and sex

\begin{tabular}{|c|c|c|c|c|}
\hline \multirow{3}{*}{$\begin{array}{l}\text { Age group } \\
\text { (years) }\end{array}$} & \multicolumn{4}{|c|}{ Persons affected } \\
\hline & \multicolumn{2}{|l|}{ Male } & \multicolumn{2}{|c|}{ Female } \\
\hline & No. & $\%$ & No. & $\%$ \\
\hline$<1$ & 19 & 0.4 & 15 & 0.3 \\
\hline $1-4$ & 228 & 5.3 & 203 & 4.9 \\
\hline $5-9$ & 488 & $11 \cdot 3$ & 448 & 10.9 \\
\hline $10-14$ & 577 & 13.5 & 535 & 13.0 \\
\hline $15-24$ & 1069 & 24.8 & 899 & 21.9 \\
\hline $25-34$ & 724 & 16.8 & 679 & 16.6 \\
\hline $35-44$ & 467 & 10.8 & 515 & 12.8 \\
\hline $45-54$ & 396 & 9.2 & 369 & 9.0 \\
\hline $55+$ & 342 & 7.9 & 431 & 10.6 \\
\hline Total & 4310 & 100.0 & 4094 & 100.0 \\
\hline
\end{tabular}

remaining $26 \%, 13 \%$ sought medical help from a hospital or general practitioner and another $13 \%$ did not take any treatment. Ninety per cent of those who used self medication used antibiotic eye ointments. The rest $(10 \%)$ used medicated eye drops. These were procured directly from chemists without any prescription from physicians. Home remedy consisted of repeated washing of the eyes with either plain water or the supernatant fluid obtained after soaking coriander seeds (Coriandrum sativum) for about $\mathbf{3 0}$ minutes.

Though viral studies of conjunctival swabs and serological examination of patients were not done, the epidemiological and clinical features were similar to those of reported epidemics of acute haemorrhagic conjunctivitis from other parts of India. ${ }^{4-6}$ It is, therefore, reasonable to believe that the outbreak in Goa was an extension of the epidemic experienced in Bombay and other parts of Maharashtra ${ }^{6}$ and Gujarat states during May and June. These are neighbouring states and there is extensive tourist traffic to Goa from these states.

Of the 8404 persons affected, 2106 were gainfully employed. They were forced to be absent from work due to conjunctivitis. Thus, 7735 man days were lost, resulting in a wage loss equivalent to Rs. $1,33,300$. With the onset of the monsoon, farming activities are in full swing in this region. There is heavy demand for agricultural labour as transplantation of rice saplings has to carried out. Many housewives and children would be employed temporarily and paid on a daily wage basis. But during this epidemic, whole families were afflicted more or less simultaneously, and therefore housewives and children could not go to work. The loss of income attributable to their absence from work due to conjunctivitis was computed based on per capita income and amounted to Rs. 95,226. Thus the estimated total loss was Rs. 2,30,290.

The cost of treatment was computed taking into consideration the money spent on eye ointments/drugs by $61 \%$ of those affected who had resorted to either self medication or had consulted a doctor. It amounted to Rs. 10,048. Medical practitioners were consulted by 1093 persons. However, the fees charge by them could not be ascertained.

Did the various regimes follower by the affected people, viz, no treatment, cheap home remedies, more expensive home remedies (antibiotic eye ointment), and professional care have different effects on the duration of illness and loss of income? This aspect was examined. But there was no appreciable difference in the duration of illness or absence from work attributable to the different regimes followed (table 2). This was not unexpected because, firstly, the mean duration of this illness is short; secondly, there is no specific treatment for the disease, ${ }^{7}$ and, thirdly, containment includes mainly increased attention to hygiene.

Interestingly, in 137 persons who were gainfully employed and who obtained professional care the mean duration of absence from work due to illness was six days $(\mathrm{p}<0.01)$, while in most of the others it was four days. Of these 137 persons $62 \%$ were employed in government or other organised agencies. They did not suffer any loss of wage in spite of a longer duration of absence from work because leave of absence was granted to them by their employers on production of a medical certificate of illness from a physician as that privilege was available to them. Most of the other affected persons were agricultural labourers who were employed on a daily wage basis. They were losing 
Table 2 Treatment regimes and mean duration of illness and absence from work due to conjunctivitis among gainfully employed

\begin{tabular}{|c|c|c|c|c|c|c|}
\hline \multirow{3}{*}{ Regime } & \multicolumn{6}{|c|}{ Duration (days) } \\
\hline & \multicolumn{3}{|l|}{ Illness } & \multicolumn{3}{|c|}{ Absence from work } \\
\hline & $\begin{array}{l}\text { No. of } \\
\text { persons }\end{array}$ & Mean & $S D$ & $\begin{array}{l}\text { No. of } \\
\text { persons }\end{array}$ & Mean & $S D$ \\
\hline No treatment & 1108 & 4 & 1.2 & 248 & 4 & 1.2 \\
\hline \multicolumn{7}{|l|}{$\begin{array}{l}\text { Home remedies } \\
\text { (a) Coriander }\end{array}$} \\
\hline $\begin{array}{l}\text { (b) Eye drops/ } \\
\text { ointments }\end{array}$ & 2926 & 3 & 1.2 & 834 & 4 & 1.2 \\
\hline \multirow[t]{2}{*}{ Professional care } & 1098 & 4 & $1 \cdot 1$ & 137 & 6 & 3 \\
\hline & $8414^{*}$ & 4 & $1 \cdot 3$ & 2106 & 4 & 1.4 \\
\hline
\end{tabular}

*10 have used both (a) and (b)

income as long as they were absent from work; hence they returned to work as quickly as possible.

It is difficult to measure economic loss to a country caused by sickness. Estimates of losses attributable to epidemics are much more difficult. It may be argued that estimates of economic loss may at best be approximations. Admittedly this is so, but they still provide an idea of the magnitude of loss. Secondly, it may be said that in a populous developing country such as India, generally not short of labour, the loss of output will be made up by others. This was less likely in the circumstances of the present epidemic, because whole families, indeed whole communities, were afflicted more or less simultaneously, so the labour reserves were also incapacitated. Thus, the economic consequences of this widespread epidemic, though of short duration, seems to be considerable. Based on the reported attack rates from different parts of India, which were in the range $24-30 \%,{ }^{46}$ an estimated 164.4 to 205.5 million persons might have been affected during the 1981 epidemic. According to a WHO study, ${ }^{8}$ an economically active population in India constitutes about $55 \%$ of men and $25 \%$ of women. From this, the man-days lost and the loss of income can be calculated. This amounted to a loss of about
657 million man-days and a wage loss of Rs. 2630 million (US \$ 219 million).

One has also to take into account the probable load on hospital and health service facilities of such an outbreak. For instance, based on physician time estimates by Rinke et al, ${ }^{9}$ approximately 264 physician man hours would have been required if all those who were affected had consulted doctors. There was a heavy demand for antibiotic eye ointments/drops, but the acute shortage of these drugs evoked considerable public outcry. The effect, if any, on other trade and tourism could not be estimated. The epidemic fortunately occurred during the south-west monsoon when the tourist season had nearly come to an end.

Indeed, the economic loss due to this epidemic, though of short duration with complete recovery from illness, is considerable and comparable to similar estimated losses from a chronic disease- tuberculosis (Rs. 2886 million or US \$ 385 million). ${ }^{8}$

\section{References}

${ }^{1}$ Wadia NH, Irani PF, Katrak SM. Neurological complications of a new conjunctivitis. Lancet 1972; ii: 970.

${ }^{2}$ Chatterjee S, Quercoopomo CO, Apontonf A. Unusual type of epidemic conjunctivitis in Ghana. Br J Ophthalmol 1970; 54: 628.

${ }^{3}$ Kono R, Sasagowa A, Ishii K, Suguira S, Ochi $M$, Matsumiya $H$, Uchida F, et al. Pandemic of a new type of conjunctivitis. Lancet 1972; ii: 1191-4.

4 Acute haemorrhagic conjunctivitis. ICMR Bull 1981; 11: 129-31.

${ }^{5}$ Gupta AK, Lamba PA, Jain RK. Epidemic acute conjunctivitis in Delhi. Afro-Asian J Ophthalmol 1982; 1: 62-5.

${ }^{6}$ Nadkarni MG, Somaiya PG. An outbreak of conjunctivitis in an Indian town-an epidemiological report. Ind $J$ Public Health 1983; XXVII: 102.

${ }^{7}$ Abell PA, De La Pena W, Harms D, et al. Acute haemorrhagic conjunctivitis in Central Africa-First enterovirus epidemic in Western Hemisphere. Ann Ophthalmol 1985; 17: 205-10.

${ }^{8}$ World Health Organization. Strategy of cholera control. BD Cholera 71·1, 1970; 4-16.

${ }^{9}$ Rinke AW, Parker RL, Alexander CA, Taylor CE. The functional analysis of health needs and service. Department of International Health. The Johns Hopkins University School of Hygiene \& Public Health, Baltimore, Maryland, USA, 1976. 